\title{
ESPAÇO DE ENCONTROS, ESPAÇO DE CONFLITOS: REFLEXÕES SOBRE A OCUPAÇÃO DO VIADUTO DO BROOKLYN EM PORTO ALEGRE ${ }^{1}$
}

SPACE FOR MEETING, SPACE FOR CONFLICT:

REFLECTIONS ABOUT THE OCCUPATION OF VIADUTO

DO BROOKLYN IN PORTO ALEGRE

Nicole Kunze Rigon

nirigon@gmail.com

Mestranda no Programa de Pós-Graduação em Antropologia Social (PPGAS/UFRGS)

Pesquisadora do Núcleo de Antropologia Visual (NAVISUAL/UFRGS)

ORCID: https://orcid.org/0000-0003-4692-3866

\section{(c) (1)(-}

Esta obra está licenciada sob uma licença Creative Commons Attribution-

-NonCommercial-ShareAlike 4.0 International License.

\section{RESUMO}

A diversidade urbana é sugestiva das discordâncias sobre como e para que os espaços coletivos deveriam ser utilizados. Com base nisso, proponho aqui uma reflexão sobre a ocupação cultural do viaduto do Brooklyn em Porto Alegre, que desencadeou uma situação conflitiva envolvendo diversos atores sociais, entre eles frequentadores dos eventos, produtores culturais e moradores da região. Reflito aqui sobre os desdobramentos desse encontro, tomando por base referências sociológicas e antropológicas sobre cidade e conflito. Para o desenvolvimento deste estudo etnográfico entre 2017 e 2018, com base na etnografia de rua (ECKERT; ROCHA, 2013) foram realizadas entrevistas, registros audiovisuais, pesquisas em acervos de imagens e jornais e observações de publicações nas redes sociais sobre o tema. O movimento de ocupação do Brooklyn teve um desfecho insatisfatório para os frequentadores e usuários do espaço, mas o caso pode ser ilustrativo da forma como têm sido administrados e negociados os usos dos espaços públicos da cidade por grupos e coletivos autônomos.

Palavras-chave: Viaduto do Brooklyn; espaço público; usos e contra-usos; conflito.

\section{ABSTRACT}

Urban diversity is suggestive of disagreements about how collective spaces should be used and also about its purposes. On this subject the reflection on the cultural occupation of Viaduto do Brooklyn, in Porto Alegre, is proposed; which has prompted a conflict situation involving 
multiple social actors, such as event-goers, cultural producers and local residents. Here, the unfolding of such meetings is reflected upon, based on sociological and anthropological references about cities and conflict. In order to develop this, ethnographic study interviews, audiovisual registers, research in image archives and journals, and observations of posts in social medias about the subjects have been performed. The Brooklyn occupation movement had an unsatisfactory outcome to its visitors and users, but that case might be illustrative of the ways in which the uses of public spaces in the city have been administrated by and negotiated with groups and autonomous collectives.

Keywords: Viaduto do Brooklyn; public space; uses and counter-uses; conflict.

\section{INTRODUÇÃO}

Os espaços públicos da cidade, repositórios das experiências de coletividade, são produzidos e frequentados por uma diversidade de atores sociais e comumente reconhecidos como espaços abertos, de livre circulação e acessíveis a todos(as). No entanto, uma série de ressalvas podem ser feitas a essas afirmações quando analisamos sociologicamente e antropologicamente os processos de ocupação dos espaços públicos pelos usuários da cidade. Inicialmente, farei algumas considerações mais gerais sobre conflito e constituição dos espaços públicos. Em seguida, me baseio no caso do viaduto do Brooklyn em Porto Alegre para ilustrar essa discussão, mas também articular outras noções, como a de espaço praticado, táticas (CERTEAU, 2012), usos e contra-usos (LEITE, 2002) para uma compreensão antropológica sobre movimentos de apropriação popular dos espaços da cidade.

Ao estudar as bases psicológicas dos tipos urbanos das metrópoles modernas, o sociólogo Georg Simmel descreve a vida no início do século XVIII na Alemanha marcada pelo rigor técnico e voltada para o trabalho e o dinheiro. Esses arquétipos, segundo ele, resultaram em uma estrutura de impessoalidade e "promoveram uma subjetividade altamente pessoal” (SIMMEL, 1967, p. 14). A atitude blasé, assim nomeada por Simmel, seria um fenômeno psíquico típico dos tipos metropolitanos modernos e estaria regendo as interações nos espaços públicos. As formas de socialização nas grandes cidades seriam, portanto, marcadas pelo individualismo e por uma "atitude mental de reserva" (SIMMEL, 1967 , p. 17), reduzindo o contato com o outro ao mero exercício da tolerância ou indiferença.

Esses sentidos da vida urbana descritos por Simmel são reatualizados na tendência observada de regulação dos ambientes públicos das cidades brasileiras, buscando sua homogeneização e elitização com base em uma visão patrimonialista dos espaços coletivos. Impulsiona- 
dos pela retórica do medo e da insegurança, ou "a fala do crime", nos termos da antropóloga Teresa Caldeira, os cercamentos de praças e privatizações de espaços de lazer renovam as formas de distanciamento social, estabelecendo novos padrões de segregação urbana (CALDEIRA, 2000). Essas estratégias de distanciamento não somente transformam a paisagem urbana, mas também determinam padrões de circulação e comportamentos adequados às ruas, praças e parques. Uma das consequências disso, segundo a autora, é a "implosão da experiência da vida pública na cidade moderna” (CALDEIRA, 2000, p. 301).

O imperativo individualista das formas de sociabilidade urbanas confluem na atrofia da capacidade de negociar significados e visões de mundo. Este fato pode estar relacionado com as resoluções insatisfatórias dos conflitos envolvendo diferentes concepções sobre a finalidade e os sentidos dos espaços públicos da cidade. Como exemplo prático deste fenômeno, se poderia citar os movimentos de ocupação de largos e praças em Porto Alegre para atividades culturais e de lazer ${ }^{2}$. Esses movimentos tensionam as formas de lazer predominantes das classes médias, voltadas para o consumo em espaços artificiais como shoppings centers e, portanto, não são aceitos como formas legítimas de apropriação dos espaços, durando pouco tempo frente às gestões disciplinantes dos espaços de convivência urbana.

O sociólogo Ezra Park (1967) argumenta que a organização da cidade e de seus espaços está relacionada à organização industrial, com base na especialização das ocupações. Essa organização colocaria os indivíduos em estado de competição, e as diferenciações entre eles promoveriam o estabelecimento de vínculos, mas também de distanciamentos sociais. Assim, de acordo com Park, a planta da cidade é composta por uma organização física e uma organização moral que estão interligadas, compondo o organismo vivo que é a cidade e a vida urbana em sua concepção. A formação das regiões morais é atribuída "em parte às restrições que a vida urbana impõe; e, em parte, à permissibilidade que essas mesmas condições oferecem" (PARK, 1967, p. 64). As regiões morais, na visão do autor, formam na cidade um mosaico de "pequenos mundos que se tocam, mas não se interpenetram". A vida urbana, com as distintas moralidades que incidem sobre ela e sobre seus espaços, vive um estado de equilíbrio instável, que "somente pode ser mantido por um processo contínuo de reajustamento" (PARK, 1967, p. 41). O reajustamento muitas vezes implica crises e impulsos de emancipação contra a ordem dominante, como os movimentos sociais. Em perpétua agitação e em constantes reajustamentos, o meio urbano, afirma Park, "intensifica os efeitos das crises" (PARK, 1967, p. 49). Nesse sentido, as crises são constitutivas do meio urbano e desencadeantes de mudanças sociais, não tendo uma conotação necessariamente negativa.

Além dos autores clássicos, diversas interpretações podem ser feitas sobre a fragmentação das cidades em espaços simbólicos e sobre como 
essas partes se relacionam. O antropólogo contemporâneo Antônio Arantes, por exemplo, ao estudar a construção social do espaço público e os embates de cidadania em São Paulo, argumenta que, entre espaços da cidade, criam-se fronteiras simbólicas "que separam, aproximam, nivelam, hierarquizam ou, numa palavra, ordenam as categorias e os grupos sociais" (ARANTES, 2000, p. 106). Diferentemente da concepção de Park sobre a impossibilidade de interpenetração das regiões morais, Arantes considera que os espaços simbólicos da cidade, dotados de moralidades e sociabilidades próprias, são "territorialidades flexíveis". Em um jogo de fronteiras, os pontos de convergência entre essas territorialidades criam zonas de contato ${ }^{3}$, deixando transparecer os conflitos e as contradições de "uma sociedade fragmentada em guerra consigo mesma" (ARANTES, 2000, p. 107).

O conflito, de acordo com o sociólogo alemão Georg Simmel, é parte constitutiva das interações sociais. Para ele, a sociedade é produto das formas de sociação que podem ser lúdicas (sociabilidade), eróticas (coqueteria) ou podem também envolver interesses específicos, como as relações de cooperação e conflito. A natureza do conflito é necessariamente social, pois nele existe o ímpeto de superar dualismos, buscando uma unidade. Assim, na concepção simmeliana, entre as formas de sociação, o conflito é "uma das mais vívidas interações" (SIMMEL, 1983, p. 122) e é compreendido como "força integradora do grupo" (SIMMEL, 1983, p. 126), na medida em que compõe a base de formação dos grupos sociais. Em síntese,

Em condição de paz, o grupo pode permitir que membros antagônicos convivam em seu interior numa situação indeterminada, porque cada um deles pode seguir seu próprio caminho e evitar colisões. Uma condição de conflito, todavia, aproxima os membros tão estreitamente e os sujeita a um impulso tão uniforme que eles precisam concordar ou se repelir completamente (SIMMEL, 1983, p. 155).

A atmosfera plural dos grandes centros urbanos no mundo globalizado é sugestiva ao aparecimento de conflitos e embates de cidadania (ARANTES, 2000). No fato de abrigar sujeitos com diferentes pertencimentos sociais, identitários e biográficos reside a possibilidade democrática, qualidade enriquecedora dos espaços públicos. Parafraseando o antropólogo Rogério Proença Leite, "somente no âmbito da vida pública, e nunca na esfera privada, as pessoas compartilham ou disputam realidades, de onde aflora a condição humana da pluralidade, base da difícil convivência social e das relações de poder" (LEITE, 2002, p. 131).

Nos contextos urbanos onde impera a diversidade, toma corpo a problemática do manejo público das diferenças entre sujeitos e grupos (ARANTES, 2002), que nem sempre convivem harmoniosamente nos espaços, exteriorizando suas discordâncias e negociando seus significados. Durante minha experiência de pesquisa etnográfica em um viaduto na região central de Porto Alegre, observei uma situação conflitiva que pode ser ilustrativa desta problemática típica dos espaços públicos nos centros urbanos. 
Assim, com embasamento nas teorias sobre cidade e conflito, especialmente influenciada pelas leituras de Michel de Certeau e Rogério Proença Leite, analiso neste artigo a ocupação cultural do viaduto do Brooklyn, que deu origem ao movimento “Ocupa Brooklyn” em 2018. Mergulhei nesse contexto em 2017 para desenvolver uma pesquisa etnográfica de conclusão de curso de graduação em ciências sociais que tinha por objetivo observar as dinâmicas socioculturais atreladas ao viaduto, as memórias do espaço, as formas de sociabilidade, bem como entender o lugar que este espaço ocupava na vida social urbana da cidade (RIGON, 2018). Tratou-se de uma pesquisa teoricamente e metodologicamente embasada na Etnografia de Rua (ECKERT; ROCHA; ZAMBONI, 2007) e na etnografia da imagem. Para o desenvolvimento do estudo foram realizadas entrevistas em campo, pesquisas em acervos de imagens, jornais locais e acompanhamento de publicações em redes sociais sobre o Brooklyn. Foram produzidas fotografias, vídeos e ilustrações, os quais foram utilizados como recursos para análise e como formas de observação etnográfica.

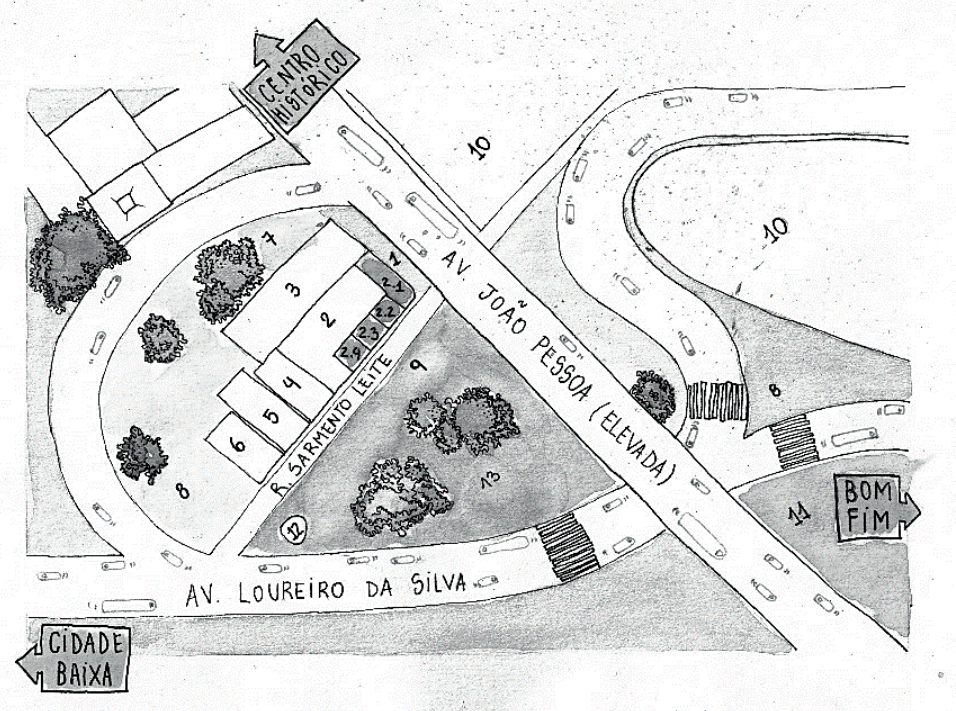

LEGENDA BROOKLYN EM 201712018

1 BeCO

2 Edifício residencial com espacis comerciais

2.1 Bar Novetrếs/Bar do Brookiyn

- 2.2 Fotocopiadora.

2.3 Espaço culturat Lechiguana

2.4 Loja bugio. Discos.

3 Edificio Residencial

4 Castelinho medieval. Edifício Residenciale sede da loja Nerdz

5 Edificio Residencial

6 Edifício Residencial e salão de jogos no térreo

7 procinha com playground infantif paco frequentada

8 Estacionamento

9 Local proibido estacionar onde sempre ha carros estacionados

10 PRédio da UFRGS

II Panta do Parque da Redencão

12 monumento do antigo relógio da empresa de tronsporte Carris cujo garagem de bondes picana sediada ali até os

I3 Largo Archimedes Fortini

Fonte: Acervo pessoal 


\section{O VIADUTO COMO ESPAÇO PRATICADO E SUAS APROPRIAÇÕES PASSAGEIRAS ${ }^{4}$}

O viaduto Imperatriz Leopoldina, também popularmente conhecido como "viaduto da João Pessoa", fica situado no cruzamento de três bairros da região central da cidade de Porto Alegre: o Centro Histórico, o Bom Fim e a Cidade Baixa. $\mathrm{O}$ arco do viaduto se sobrepõe a um largo que interliga esses três bairros, conhecidos como distritos culturais e boêmios da cidade ${ }^{5}$. O largo, composto por prédios residenciais e espaços comerciais, é delimitado por duas importantes avenidas, a João Pessoa e a Loureiro da Silva.

No largo encontra-se há mais de 20 anos uma loja de jogos de tabuleiro e revistas em quadrinhos cuja fachada tem formato de um castelo medieval com torres, grades quadriculadas nas janelas e paredes de pedra. Além dessa loja, no andar térreo de um dos prédios há uma galeria com pequenas salas comerciais onde funcionavam uma gráfica fotocopiadora, dois bares e uma loja de discos. Os bares e a loja de discos, que também vendia cerveja (itens $2.1,2.3$ e 2.4 na ilustração acima), eram pequenos espaços sem estrutura para acomodar mais que meia dúzia de pessoas em seu interior. A rua era uma extensão dos estabelecimentos. Os frequentadores compravam suas bebidas e ficavam aglomerados, socializando em frente aos bares, no largo ou embaixo do viaduto.

No entorno do largo avistamos outros importantes espaços e edificações. No largo, se nos posicionarmos de frente para a avenida Loureiro da Silva, logo em frente avistamos o Parque da Redenção ${ }^{5}$, o prédio administrativo da Secretaria Municipal de Saúde, uma agência bancária e um edifício de salas comerciais. Mais à esquerda avistamos prédios históricos da Universidade Federal do Rio Grande do Sul. Na próxima quadra, à direita, está situado um hotel de alto padrão recentemente construído. A paisagem composta pelo viaduto e seu entorno evidencia uma área de confluência de edificações comerciais, agências de serviços públicos, hotelaria, além de antigos prédios residenciais. Nesse contexto, a vida urbana tem um fluxo acelerado e barulhento ritmado pelos automóveis, ciclistas, caminhantes apressados, trabalhadores, catadores, pessoas em situação de rua, turistas, estudantes e skatistas. São eles os próprios praticantes ordinários da cidade, nos termos de Michel de Certeau (2012).

Segundo Certeau (2012), são os sujeitos urbanos, usuários da cidade, que, através de suas experiências, transformam os lugares da cidade em espaços praticados. As formas de apropriação urbanas podem ser compreendidas, nos termos de Certeau, como maneiras de fazer. Elas são modalidades da ação que produzem identificações com o lugar, transformando-o e sendo transformadas por ele em uma relação dialógica. A ação humana é o que faz do espaço um lugar praticado (CERTEAU, 2012, p. 184).

Dado que a construção do espaço está relacionada aos usos e às apropriações que os sujeitos fazem de um determinado lugar, considero 
importante diferenciar brevemente as noções de espaço urbano e espaço público. Me filio à diferenciação proposta por Rogério Leite (2002), muito inspirado por Michel de Certeau, para falar sobre os processos de reativação dos espaços públicos no Recife Antigo, em que ele analisa as diferenças entre processos de gentrification e de apropriação autônoma. Os espaços urbanos, para o autor, são uma referência espacial e estão mais relacionados ao espaço físico e à estrutura material da cidade. Já os espaços públicos possuem dimensões vivenciais e simbólicas que os constituem. O caráter público de um espaço depende mais das práticas humanas do que de sua estrutura material urbana. Essa conceitualização é fundamental para o seu argumento sobre os usos e contra-usos dos espaços (LEITE, 2000), cujas atribuições dependem da natureza da ação, ou das maneiras de fazer, com que os sujeitos se engajam na produção dos espaços públicos.

$\mathrm{O}$ viaduto da João Pessoa viveu diferentes regimes de ocupação ao longo de sua história, cada um marcado por diferentes interações sociais. Buiu Rodriguez, músico, skatista, produtor cultural e sócio de um dos bares que havia no Brooklyn, remonta cenas do passado do viaduto através de fragmentos biográficos compartilhados em uma entrevista realizada ao som de rap numa noite quente de novembro de 2017. Ele conta que, desde o final dos anos 1990, os skatistas já frequentavam o espaço e anos mais tarde construíram obstáculos para executar manobras, atribuindo "essa identidade do skate embaixo do viaduto". Ali surgiu também o Beco, uma casa noturna reconhecida pelas festas com músicas indie, e uma das primeiras lojas de graffiti da cidade. A construção gradual de uma cena alternativa, embebida na cultura hip-hop desde a década de 1990, foi o que conflagrou a atmosfera underground e transgressora deste espaço, que era conhecido como "o pico do viaduto" e depois veio a ser chamado de Brooklyn:

Não sei quem deu esse nome. Foi o que pegou apreço e virou viaduto do Brooklyn. Ele surgiu do fluxo da casa noturna, da loja de graffiti e depois por resistência dos meninos do skate. Nessa pegada que surgiu toda essa função (BUIU RODRIGUEZ, 2017).

Por volta de 2009, a organização social Central Única das Favelas (CUFA), que desenvolvia no espaço torneios de basquete de rua e outras atividades de prevenção às drogas, recebeu uma concessão da prefeitura garantindo os direitos da instituição aos usos do espaço. Havia um projeto de construir ali um centro social com salas de aula e academia, que não teve continuidade. Ainda no âmbito das atividades filantrópicas, desde 2016 existe um coletivo que todos os sábados distribui comida para a população em situação de rua, beneficiando cerca de 650 pessoas semanalmente, que formam grandes filas no viaduto e no entorno.

Mais recentemente, em 2016, a inauguração de bares e de uma loja de discos de vinil no Largo Archimedes Fortini (item 13 na ilustração acima) começou a atrair muitas pessoas ao viaduto. A presença de pro- 
dutores culturais no espaço pode ter sido um fator que impulsionou a agregação das pessoas. O Brooklyn ganhou popularidade no cenário jovem da cidade também através da Batalha do Brooklyn (BDB), organizada por coletivos de Slam - batalhas de poesia -, que promovem encontros em diversos pontos da cidade. Além disso, as festas e as feiras de economia criativa começaram a dar corpo a um público volumoso frequentador semanal do Brooklyn.

O Brooklyn foi se tornando um espaço heterogêneo utilizado por diferentes grupos sociais e coletivos que se distinguiam por preferências musicais, estilos de vida, classe social e orientações políticas. $\mathrm{O}$ espectro da diversidade na programação cultural se estendia desde o ensaio do grupo de maracatu até o festival de música punk. Todos esses grupos sociais, no entanto, compartilhavam algum grau de identificação com posicionamentos políticos a favor da diversidade. A maioria dos frequentadores eram jovens e estudantes que em sua retórica evocavam a importância das ocupações na democratização dos espaços públicos. Poderíamos distingui-los entre os que consumiam cerveja artesanal, "polar latão"7 ou "kits"; entre os adeptos da roda de samba e os do rock'n'roll; entre os que viravam a noite na festa de cúmbia e os que frequentavam feiras de economia criativa aos domingos de tarde. Esses diferentes comportamentos de consumo e os diferentes símbolos compartilhados apontam para pertencimentos de classe e estilos de vida distintos, fazendo com que o Brooklyn possa ser narrado tanto como um lugar de consumo da classe média, quanto como "um lugar de resistência, [...] onde as pessoas da periferia se encontram no centro" (Entrevista com Tiry, 2017)9.

O ano de 2017 foi marcado por uma intensa programação de shows de samba, rock, rap, ensaios de grupos de percussão, teatro de rua, festas temáticas na rua, feiras de vinil, brechós e festivais. Os eventos eram organizados e divulgados nas redes sociais e chegavam a juntar milhares de pessoas no viaduto. Cada elemento da programação atribuía diferentes visualidades ao espaço. Foi assim que o Brooklyn se tornou um notório espaço de manifestações culturais e de participação popular na cidade, reconhecido inclusive nos jornais locais, que divulgavam os eventos. As diferentes formas de apropriação do espaço que sucediam umas às outras, distinguindo as práticas diurnas das práticas noturnas e que foram incorporadas à simultaneidade dos fluxos imagéticos e sonoros no viaduto fizeram dele um espaço urbano efervescente, que vivenciava um momento particular e efêmero em sua história no momento em que desenvolvi a pesquisa. 

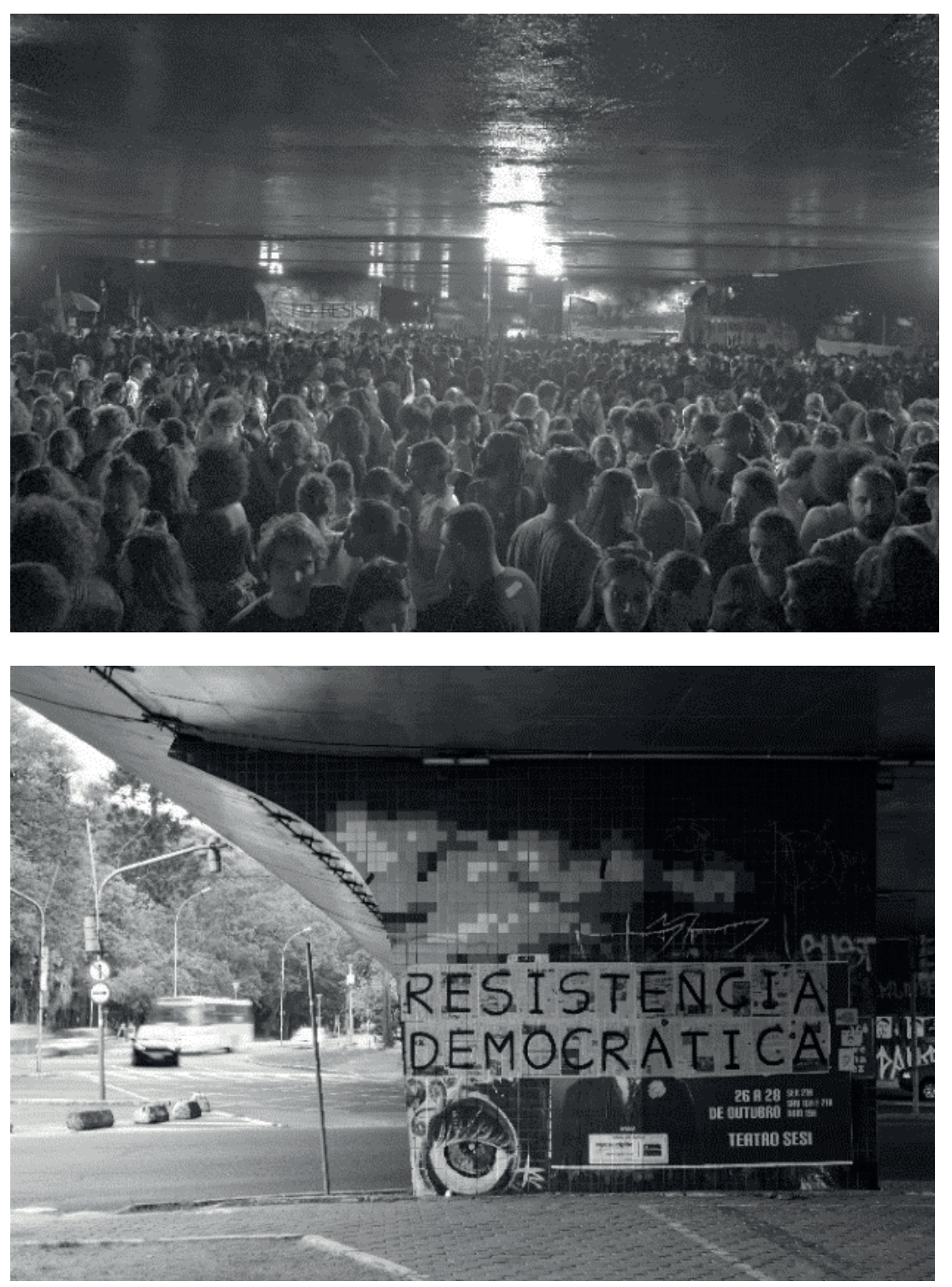

Fotografias da autora em trabalho de campo, 2018. Fonte: acervo pessoal.

Esse fértil período teve a duração de um breve instante no curso dos acontecimentos que marcam os espaços da cidade. Em meados de 2018, os moradores dos prédios na região, queixando-se do excesso de barulho, mobilizaram-se contra o movimento de ocupação. A partir de um ก abaixo-assinado, foi instaurada uma atmosfera conflitiva que resultou, por fim, na interdição dos bares e na suspensão dos eventos embaixo do viaduto. Detalharei mais precisamente essa situação adiante.

Os diferentes regimes de ocupação do viaduto agregaram novos sentidos e significados ao espaço. Também se transformaram as representações no imaginário coletivo daquele lugar, considerado antes como degradado, perigoso e pouco frequentado. Compreender analiticamente um determinado espaço na cidade como praticado, implica ser testemunha da produção de novas narrativas, novas perspectivas e novos conteúdos que são atribuídos às formas de um lugar através das artes de 
fazer. Os praticantes inscrevem novas linhas no texto urbano. Assim, "as redes dessas escrituras avançando e entrecruzando-se compõem uma história múltipla, sem autor nem espectador, formada em fragmentos de trajetórias e em alterações de espaços: com relação às representações, ela permanece cotidianamente, indefinidamente, outra" (CERTEAU, 2012, p. 159).

As formas de apropriação do viaduto por indivíduos e grupos autônomos visando democratizar e desvelar novas atribuições aos espaços urbanos em desuso se inscrevem no domínio das ações táticas, no sentido que Certeau dá ao termo. Em contraposição às estratégias - conjunto de práticas que articulam espaço e poder -, as táticas são movimentos imprevisíveis que sacodem a cidade, "procedimentos resistentes, astuciosos e teimosos" (CERTEAU, 2012, p. 163). Destituídas de poder e de um lugar próprio, as táticas subvertem sentidos de espaços estratégicos, externalizando contradições entre formas de produção e gestão dos lugares (usos prescritos) e suas formas de apropriação (contra-usos).

A observação etnográfica da vida social no viaduto mostra que ele é muito mais do que um lugar de passagem ou uma estrutura urbana para otimização dos fluxos de automóveis. Os indivíduos e grupos, em suas formas de sociação, dão vida àquele espaço, ressignificando modelos e planejamentos urbanos. Essas significações, ou contra-sentidos, como sugere Leite, "diferem daqueles esperados pelas políticas urbanas, (e) contribuem para uma diversificação dos atuais sentidos dos lugares" (LEITE, 2002, p. 121).

A distinção entre usos e contra-usos, estabelecida por Leite, é utilizada para pensar os processos de reanimação dos espaços urbanos. Os contra-usos, segundo ele, subvertem os usos esperados de um espaço regulado. Eles são as práticas que jogam com o espaço disciplinar e se proliferam de formas criativas num ato de "captação espacial" (CERTEAU, 2012, p. 177), balizando as regulações impostas. Nesse sentido, podemos considerar o movimento de ocupação do Brooklyn como um contra-uso, ou como uma apropriação tática, uma vez que reativou a vida urbana e alterou significativamente os sentidos daquele espaço.

Por fim, gostaria de chamar atenção ao caráter subjetivo de construção do Brooklyn enquanto espaço praticado. A ocupação reflexiva e discursiva do espaço pelos seus frequentadores politiza a paisagem urbana e a participação social. Cria-se no espaço uma dimensão simbólica que somente pode ser acessada e reconhecida pela participação e engajamento na experiência urbana. Isto é, o Brooklyn, quando dissociado da experiência sensorial e simbólica que proporciona, é somente o "viaduto da João Pessoa".

Assim, "Brooklyn" reverencia o antigo subúrbio negro de uma das maiores cidades do mundo, um dos berços das expressões artísticas da cultura urbana nos anos 1970, como o graffiti e o rap. Atualmente, o viaduto, com seus graffiti, equipamentos para manobras de skate e batalhas 
de rimas, orquestra símbolos que reverenciam práticas de seu passado e também os contra-usos que fazem dele um espaço de ação simbólica pelo direito à cidade e de resistência no centro da cidade de Porto Alegre. "Brooklyn", portanto, designa todo esse universo de experimentações e significados atribuídos pelos praticantes do espaço, marcando o imaginário coletivo com suas formas de sociabilidade particulares.

\section{A EFEMERIDADE DOS PROCESSOS DE OCUPAÇÃO DOS ESPAÇOS PÚBLICOS EM PORTO ALEGRE}

A pluralidade característica do meio urbano cria condições para os encontros entre indivíduos e grupos com diferentes opiniões e interesses. No caso do Brooklyn, a convivência harmônica entre os frequentadores dos eventos e os moradores dos edifícios residenciais durou pouco. O que alguns empresários locais convencionaram chamar de "política da boa vizinhança", orientada por um princípio de não interferência entre as dinâmicas sociais de cada grupo que utilizava o espaço, perdurou somente enquanto o público frequentador ainda era pequeno e não criava grandes aglomerações. $\mathrm{O}$ aumento da circulação de pessoas no espaço era considerado positivo pelos moradores, pois garantia maior fluxo, consequentemente mais visibilidade para o comércio e segurança para o entorno.

A cena cultural que vinha se configurando no espaço desde o final de 2016 atingiu seu clímax ao final de 2017. A partir daí, a recorrência dos eventos com públicos volumosos começou a gerar conflitos entre moradores e frequentadores do espaço. Em abril de 2018, os moradores produziram um abaixo-assinado que levou o Ministério Público a abrir um inquérito para apurar denúncias acerca do barulho e do desrespeito ao horário de silêncio ${ }^{10}$. Neste processo aconteceram audiências, reuniões para negociação de condutas e criou-se uma comissão de diálogo, composta por representantes dos coletivos autônomos que ocupavam o espaço, além de alguns moradores favoráveis à ocupação. A partir disso, o público frequentador também se engajou com expressividade na defesa do Brooklyn, criando espontaneamente uma página no Facebook intitulada "Em defesa do Brooklyn". As noites de terça-feira, da tradicional roda de samba com a banda Encruzilhada do Samba, passaram a ser noites de resistência e de manifestações em defesa da livre manifestação cultural nos espaços públicos da cidade. A iminência do cancelamento dos encontros foi um fator agregativo para os frequentadores das rodas de samba, e o público parecia ainda maior a cada evento.

A respeito do engajamento político na defesa do espaço, Leite (2002) argumenta que a construção social dos lugares tem o efeito de politizar o espaço urbano. Os vínculos construídos pelas pessoas com o espaço ocupado geram sentimentos de pertencimento e engajamento. Por isso, na emergência do conflito, o Brooklyn, além de ser um espaço de lazer e cultura, passou a ser também um espaço político de contestação. 
Buscando constituir unidades organizadas em torno de interesses e valores comuns, tanto os moradores quanto os frequentadores e os organizadores dos eventos se organizaram coletivamente. Na prática, esses arranjos permitem visualizar o conflito como instância integradora dos grupos e também a interligação entre os aspectos negativos e positivos do conflito (SIMMEL, 1983). Por um lado a existência do conflito atua como potência unificadora do grupo e, por outro, pode implicar a aniquilação de uma das partes, uma vez que o conflito, segundo Simmel, tem por objetivo a resolução de dualismos divergentes. "Uma certa quantidade de discordância interna e controvérsia externa estão organizadamente vinculadas aos próprios elementos que, em última instância, mantêm o grupo ligado" (SIMMEL, 1983, p. 126). De todo modo, uma interpretação simmeliana nos leva a considerar o conflito como uma constante nas interações sociais no meio urbano, agindo como força reguladora do equilíbrio instável da vida urbana.

Após a abertura do inquérito no Ministério Público, as fiscalizações da polícia se tornaram recorrentes, e foram adotadas algumas estratégias controversas para afugentar o público, como o confisco das cervejas à venda no local. Apesar do esforço do movimento social, as aglomerações foram pouco a pouco perdendo força ao longo de 2018. A situação se agravou ainda mais quando o Ministério Público decretou o fechamento dos bares que forneciam infraestrutura para os eventos.

Os decretos judiciais que culminaram no fechamento dos bares alegavam irregularidades nos registros dos estabelecimentos, mas não abordavam as queixas dos moradores a respeito do ruído sonoro. $\mathrm{O}$ que se pôde observar nos eventos após o fechamento dos bares foi que a estratégia adotada pelo poder público para dissipar as aglomerações foi restringir ao máximo as possibilidades e as condições de os eventos acontecerem. Minando a ocupação pelas beiradas, a Secretaria Municipal da Produção, Indústria e Comércio (SMIC) aumentou a fiscalização e o confisco de bebidas nos eventos. A Força Gaúcha de Pronta Resposta da Brigada Militar marcava presença no Brooklyn constantemente, e o alvo principal do policiamento eram os frequentadores. Setembro e outubro de 2018 foram meses críticos para o movimento "Em defesa do Brooklyn" devido às ações truculentas da Brigada Militar, criminalizando a presença das pessoas no espaço e afugentando o público com gás lacrimogênio.

Entre negociações, propostas e contrapropostas com o Ministério Público, sem resoluções satisfatórias, foi havendo um desgaste no movimento. A banda Encruzilhada do Samba que tocava às terças-feiras no viaduto passou a ser o único mediador entre os frequentadores e o Ministério Público. Os custos para continuar tocando no Brooklyn ficaram altos após o fechamento do bar que fornecia caixas de som e energia elétrica. Assim, no dia 30 de outubro de 2018, aconteceu a derradeira roda de samba no Brooklyn. 

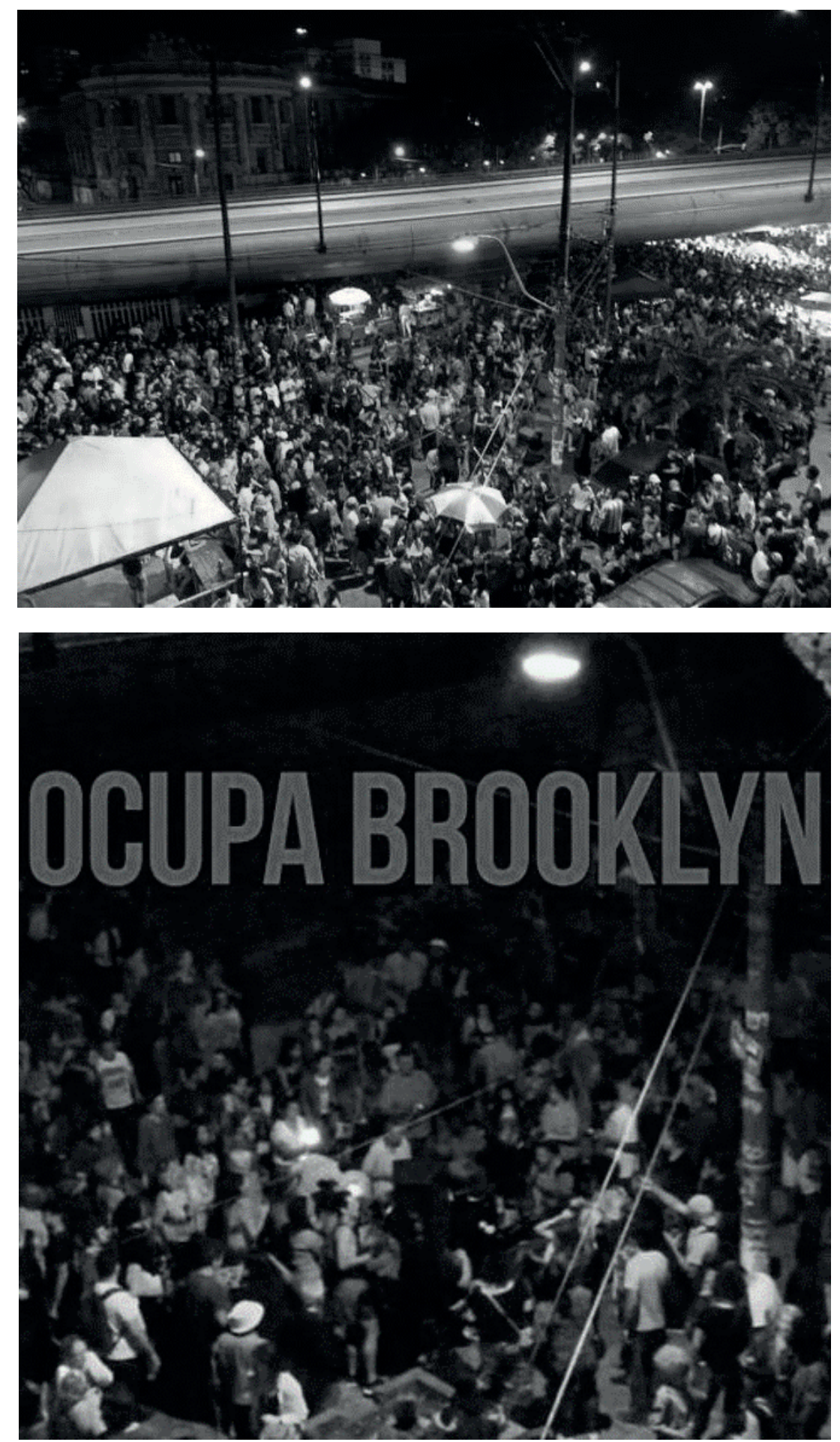

Fonte: Página do Facebook chamada "Em defesa do Brooklyn".

A desigualdade de forças políticas e simbólicas (e também físicas, no caso da polícia) entre as instituições reguladoras e os movimentos autônomos de ocupação torna-se cada vez mais representativa de uma cidade que administra seus espaços públicos com uma ideação patrimonialista. A itinerância entre os lugares da vida noturna, criando novos cenários e novos vínculos, tem sido uma forma tática de apropriação 
dos espaços para garantir a sobrevivência dos movimentos que reivindicam a vocação, por excelência, dos espaços públicos: serem abertos, gratuitos, livres e de todos(as). No entanto, cada vez que colidem políticas de controle e movimentos autônomos, existe um padrão nos processos de urbanização que se reatualiza, em que os aspectos materiais urbanos prevalecem sobre os vivenciais.

Típicas da cena noturna porto-alegrense, as dinâmicas migratórias são táticas desenvolvidas em espaços estratégicos para garantir a sobrevivência da vida noturna, subvertendo os usos esperados de um espaço regulado. Elas reanimam a vida nos espaços ermos da cidade, acionando seus contra-usos (LEITE, 2002). A banda Encruzilhada do Samba costuma tocar nos diferentes espaços públicos da cidade, em um movimento itinerante a banda faz "arqueologia dos espaços alternativos", como nomeou Luciana Mello, uma das integrantes da banda. De certo modo, é essa arqueologia dos espaços que parece estar regendo a movimentação de grupos pelas territorialidades da vida noturna, conflagrando novos pontos de lazer e de encontro na cidade.

Retornando alguns capítulos na história da boemia porto-alegrense, notamos que esse movimento migratório se reinventa com o passar dos anos, construindo novos espaços desde a década de $1970^{11}$. Inicialmente a "Esquina Maldita", próxima ao campus central da Universidade Federal do Rio Grande do Sul, era o ponto onde estudantes se reuniam à noite para beber. Essa cena se expandiu para o Bom Fim no período de maior abertura política e, por volta dos anos 1980, a juventude boêmia havia tomado as ruas do interior do bairro. Junto com o aumento de jovens nas ruas, houve o aumento também no consumo de substâncias ilícitas, que começou a atrair traficantes ao bairro. Era preciso reduzir o público que ficava à deriva nas ruas pela madrugada usando drogas e gerando intrigas. Foi assim que tiveram início as repressões policiais desse tipo e foram impostas novas regulamentações à vida noturna: os bares não poderiam mais funcionar durante toda a madrugada, não podendo continuar abertos após a meia-noite.

$\mathrm{O}$ aumento das repressões policiais e do disciplinamento dos usos dos espaços do Bom Fim fez com que a cena boêmia se deslocasse para a Cidade Baixa na década de 1990. O movimento foi se intensificando, e as ruas foram novamente tomadas por uma juventude festiva e embriagada, transformando o bairro no novo distrito boêmio da cidade. No entanto, a aglomeração de pessoas nas ruas não ficou isenta das regulações da gestão pública dos espaços, e começou a haver sucessivas ondas de repressão às aglomerações nas ruas da Cidade Baixa. O público frequentador do Brooklyn era em parte o mesmo público frequentador da Cidade Baixa, dada a proximidade dos espaços.

O conflito aqui descrito é recorrente em Porto Alegre, sobretudo na Cidade Baixa, que frequentemente figura no noticiário local como espaço em disputa entre antigos moradores do bairro e jovens frequenta- 
dores $^{12}$. Por isso, no caso do Brooklyn, este conflito de maior escala se sobressaiu entre as contradições que emergem a partir da confluência de grupos e pessoas na esfera pública, tendo maior repercussão nas mídias e gerando debates. No entanto, é preciso atentar para as diversas facetas dos conflitos e contradições que residem nos espaços. A imersão etnográfica no contexto permitiu visualizar outros temas que geravam discordâncias em menor escala, como o consumo de drogas ilícitas, a presença de vendedores ambulantes de cervejas e lanches, os carros estacionados em local proibido, o lixo, a responsabilidade com a higiene do espaço, entre outros.

Frente à intensificação das práticas disciplinantes dos espaços públicos da cidade nos últimos anos, as aglomerações noturnas nas ruas da cidade estão cada vez mais escassas. Tendo em vista o êxito das políticas de controle urbano em impedir as aglomerações de acontecerem, o fenômeno do Brooklyn parecia balizar as políticas de controle e por isso se constituiu como um espaço de resistência na cidade. Somado a isso, a falta de políticas culturais e de espaços apropriados para essas formas de sociabilidades urbanas na cidade é o que faz com que, de tempos em tempos, surjam, de forma autônoma e orgânica, movimentos de ocupação dos espaços, como foi o caso do Brooklyn.

O caso do Brooklyn é ilustrativo para tratar das segmentações simbólicas da vida urbana coletiva e das distintas moralidades que incidem sobre ela. Analisar a construção social dos espaços da cidade é importante para entender a politização desses espaços, bem como os processos e as táticas adotadas pelos usuários para legitimar sua presença no local. Tudo isso passa pela experiência do conflito, em que se externalizam os princípios e valores que regem as interações entre diferentes sujeitos e grupos no meio urbano. $\mathrm{Na}$ análise dessa situação, considero importante, sobretudo, observar como as experiências urbanas permitem aos sujeitos conhecerem outras formas de participação e engajamento na vida pública, mesmo que suas motivações para frequentar os espaços não sejam inicialmente políticas.

\section{CONSIDERAÇÕES FINAIS E OUTROS QUESTIONAMENTOS}

A efemeridade do movimento de ocupação do Brooklyn faz pensar sobre a dimensão temporal das apropriações criativas dos espaços, que perduram ao longo do tempo em um movimento migratório, se renovando a cada descoberta de um espaço na cidade.

Talvez o êxito da duração deste fenômeno resida no fato de que as táticas são destituídas de um lugar que lhes seja próprio, isto é, seus lugares pertencem à coletividade ${ }^{13}$. Deste modo, a sobrevivência das táticas depende de que o desejo de continuar nas ruas reativando novos espaços seja maior que a vontade de ter um espaço próprio e exclusivo. A capacidade de transformação e reordenação das práticas conforme o contexto permite vislumbrar outras possibilidades de ação na abundân- 
cia de lugares que a cidade oferece. As táticas jogam com os terrenos que não lhes são próprios sem querer apreendê-los. As táticas são práticas criativas, formas de expressão e resistência que se reinventam nos territórios da vida urbana, fazendo deles espaços praticados.

O fenômeno de ocupação do Brooklyn, que teve a duração de aproximadamente dois anos, seguiu uma tendência que se observa historicamente nos movimentos de apropriação das ruas e das praças de Porto Alegre. As dinâmicas migratórias são características desses movimentos na história da vida noturna e das sociabilidades de rua na cidade. $\mathrm{O}$ viaduto foi um lugar de passagem desse fluxo que se orienta por uma arqueologia dos espaços alternativos e segue seu curso, tornando públicos novos (e antigos) espaços da capital.

Resguardando as particularidades de cada movimento de ocupação, todos compartilham um ideário de ocupação dos espaços para atribuir-lhes novos usos. Transgressores, no sentido de serem procedimentos populares que tensionam as estruturas de poder regulamentadoras dos espaços, os movimentos são também protestos contra os poderes públicos que negligenciam as políticas públicas e instituições de artes, cultura e entretenimento.

A recente inauguração da Orla Moacyr Scliar (2018), reformada após anos fechada ao público, tem levado milhares de pessoas diariamente ao novo cartão-postal da cidade, lotando o espaço de dia e de noite. Isso demonstra a carência da população por espaços de compartilhamento de experiências urbanas e de renovação dos vínculos de pertencimento com a cidade. Investir nesses espaços de modo a proporcionar sua fruição livre e gratuita à população significa investir também em cidadania, participação social e democratização dos espaços urbanos.

Neste artigo, procurei mostrar alguns dos diferentes regimes de ocupação do viaduto Imperatriz Leopoldina ao longo de sua história e a diversidade de expressões que emergem em meio à simultaneidade de acontecimentos que habitam aquele espaço. Ao descrever o processo de ruptura da cena cultural no Brooklyn, procurei elaborar ilustrativamente o argumento simmeliando da regularidade dos conflitos nas interações sociais urbanas.

O tempo passa, as populações e seus interesses se renovam, mas os conflitos, de certo modo, condicionam a existência da vida urbana e externalizam as discordâncias entre os sujeitos, construindo as bases de uma sociedade plural e democrática. Na história do viaduto, desde sua construção em 1974, ele já se constituía como espaço de participação política. No mesmo local em que recentemente jovens de diversas camadas sociais protestaram pelo direito ao espaço, naquela época, em plena ditadura militar, estudantes universitários protestavam contra o corte de árvores que precedeu o início das obras de construção do viaduto.

Embora a situação conflitiva não tenha tido um desfecho satisfatório para os frequentadores usuais do viaduto, a existência do conflito não 
deve ser vista como negativa, mas na verdade como uma potência transformadora das relações e dos espaços, seja para reafirmar uma ordem dominante, seja para tensioná-la.

Espero que o caso do viaduto do Brooklyn em Porto Alegre possa servir como um instrumento tanto para compreender outras dinâmicas de ocupação dos espaços, quanto para ressaltar a importância política desses atos. Iniciei abordando a condição plural e democrática das experiências compartilhadas no meio urbano. Concluo afirmando que as formas de apropriação dos lugares da cidade inauguram novas territorialidades e reivindicam direitos, nos termos de Rogério Leite, "direitos de pertencer à cidade, de estabelecer itinerários próprios, de fazer do espaço público contemporâneo, enfim, um legítimo espaço político da diferença" (LEITE, 2002, p. 130).

\section{NOTAS}

1. Agradeço à Comissão organizadora da VIII edição do Prêmio Lévi-Strauss e à Associação Brasileira de Antropologia pelo reconhecimento oferecido a esse trabalho. Uma versão inicial do texto foi apresentada no GT "Culturas juvenis de rua no século XXI: transgressão, criatividade e resistência", coordenado por Ricardo Campo (Nova FCSH) e Alexandre Barbosa Pereira (UNIFESP), na XIII Reunião de Antropologia do Mercosul. Agradeço a todos/as que participaram do GT e fizeram contribuições para a construção desse artigo, à minha orientadora Cornelia Eckert e aos pesquisadores e pesquisadoras do Navisual, em especial à Marina Bordin Barbosa, amiga e parceira de pesquisas e reflexões.

2. Como a Serenata Iluminada, Largo Vivo, Movimento Cais Mauá de Todos, as noites de Tutti Giorni no Largo dos Açorianos, Luau Autônomo na Orla do Guaíba, Ocupa Brooklyn, Arruaça, entre outros.

3. Segundo Arantes (2000), ruas e praças públicas podem ser consideradas zonas de contato.

4. Situando-me no tempo, é importante salientar que este artigo consiste em um retrato de um momento específico na história do viaduto. Trata-se do período entre os anos 2016 e 2018, que foi marcado por uma intensa movimentação cultural e por uma riqueza de acontecimentos em seu cotidiano. Das formas de sociabilidade observadas naquele período, poucas podem ser observadas ainda hoje. Foi um movimento de ocupação temporário, mas significativo para a história dos lugares da cidade. Por essas razões, embora se trate de um período recente, utilizarei os verbos conjugados no passado.

5. O Bom Fim, o Centro e principalmente a Cidade Baixa são considerados polos de lazer e de vida noturna na cidade devido à alta concentração de bares e de atividades culturais nessas regiões. Diversas etnografias contextualizam esses espaços. Alguns desses estudos podem ser encontrados na coletânea "Etnografia de rua: Estudos de antropologia urbana” (CUNEGATTO, 2013; MARQUES, 2013; RODOLPHO, 2013; SILVEIRA, 2013).

6. Conhecido popularmente como Parque da Redenção, o Parque Farroupilha é um dos principais parques da cidade e fica localizado no bairro Bom Fim. É reconhecido como ponto turístico da capital e também pelas tradicionais feiras 
de alimentos orgânicos aos sábados e de artesanato local aos domingos. A esse respeito ver Eckert; Rocha; Zamboni, (2007).

7. Cerveja popular com forte apelo identitário gaúcho.

8. Bebida feita a partir da mistura de vodca com energético, consumida por jovens e adolescentes em garrafas de 2 litros ou partilhada em copos descartáveis. 9. Rapper e liderança comunitária no bairro Rubem Berta, na zona norte de Porto Alegre. Foi organizador do Festival Zumbi dos Palmares, que aconteceu no Brooklyn, em novembro de 2017, evento que integrou a agenda cultural da cidade no mês da consciência negra.

10. "MP abre inquérito para apurar barulho no 'Brooklyn' de Porto Alegre". Gaúcha ZH. Disponível em:<https://gauchazh.clicrbs.com.br/porto-alegre/noticia/2018/04/mp-abre-inquerito-para-apurar-barulho-no-brooklyn-de-porto-alegre-cjg6zfloh01le01qlx0krbxsb.html>. Acesso em: 28 maio 2020.

11. A deriva da boemia pelos ambientes públicos na cidade e as mudanças na vida noturna nos redutos boêmios do bairro Bom Fim foi estudada e detalhadamente descrita na dissertação de mestrado de Lucio Fernandes Pedroso (PEDROSO, 2009).

12. Para saber mais a esse respeito ver (REIS, 2013).

13. "Denomino (...) 'tática' um cálculo que não pode contar com um próprio, nem portanto com uma fronteira que distingue o outro como totalidade visível. A tática só tem por lugar o do outro" (CERTEAU, 2012, p. 45).

\section{REFERÊNCIAS}

ARANTES, Antônio A. Paisagens paulistanas: transformações do espaço público. São Paulo: Imprensa Oficial, 2000.

CALDEIRA, Teresa P. Cidade de muros: crime, segregação e cidadania em São Paulo. São Paulo: Ed. 34/Edusp, 2000.

CERTEAU, Michel de. A invenção do cotidiano: 1. Artes de fazer. 19. ed. Petrópolis: Vozes, 2012.

CUNEGATTO, Thais. Etnografia da e na Rua da Praia: cotidiano, memória e formas de sociabilidade no cetro urbano porto-alegrense. In: ROCHA, Ana Luiza Carvalho da; ECKERT, Cornelia. Etnografia de rua: estudos de antropologia urbana. Porto Alegre: Editora da UFRGS, 2013.

ECKERT, Cornelia; ROCHA, Ana Luiza C. da; ZAMBONI, V. Percorrendo as marcas de distintas temporalidade no Bairro Bonfim: exercício de etnografia nas ruas de um bairro. Iluminuras, v. 8, n. 17, p. 1-21. 3 jun. 2007.

LEITE, Rogério Proença. Espaço público e política dos lugares: usos do patrimônio cultural na reinvenção contemporânea do Recife Antigo. Tese (Doutorado) - Universidade Estadual de Campinas, Instituto de Filosofia e Ciências Humanas, Programa de Pós-Graduação em Antropologia, Campinas, São Paulo, 2001.

LEITE, Rogério Proença. Contra-usos e espaço público: notas sobre a construção social dos lugares na Manguetown. Revista Brasileira de Ciências Sociais, v. 17 n. 49, p. 115-172, 2002. 
MARQUES, Olavo Ramalho. A poética do vivido: uma etnografia do cotidiano na Cidade Baixa Porto Alegre/RS. In: ROCHA, Ana Luiza Carvalho da; ECKERT, Cornelia. Etnografia de rua: estudos de antropologia urbana. Porto Alegre: Editora da UFRGS, 2013.

PARK, Robert E. A cidade: sugestões para a investigação do comportamento humano no meio urbano. In: VELHO, Otávio. O fenômeno urbano. Rio de Janeiro: Zahar, 1967.

PEDROSO, Lucio Fernandes. Transgressão do Bom Fim. Dissertação (Mestrado) - Instituto de Filosofia e Ciência Humanas, Universidade Federal do Rio Grande do Sul, Programa de Pós-Graduação em História, Porto Alegre, 2009.

REIS, Vanessi. Do Bom Fim à Cidade Baixa: o uso dos espaços de lazer noturno (1964-2006). 2013. Dissertação (Mestrado) - Pontifícia Universidade Católica do Rio Grande do Sul, Porto Alegre, 2013.

RIGON, Nicole K. Sociabilidade, conflito e resistência: etnografia no viaduto do Brooklyn em Porto Alegre. Trabalho de conclusão de Curso (Graduação) - Universidade Federal do Rio Grande do Sul, Porto Alegre, 2018.

ROCHA, Ana Luiza C. da; ECKERT, Cornelia. Etnografia de rua: estudos de antropologia urbana. Porto Alegre: Editora da UFRGS, 2013.

RODOLPHO, Patricia. Encontrando Imagens na e da Rua da Praia: relato de uma etnografia de rua. In: ROCHA, Ana Luiza Carvalho da; ECKERT, Cornelia. Etnografia de rua: estudos de antropologia urbana. Porto Alegre: Editora da UFRGS, 2013.

SILVEIRA, F. L. da. Beco, rua, avenida: sociabilidades e redes de vizinhança em um lugar de acolhimento. In: ROCHA, Ana Luiza Carvalho da; ECKERT, Cornelia. Etnografia de rua: estudos de antropologia urbana. Porto Alegre: Editora da UFRGS, 2013.

SIMMEL, Georg. A natureza sociológica do conflito. In: FILHO, Evaristo de Moraes. Georg Simmel: sociologia. São Paulo: Ática, 1983.

SIMMEL, Georg. Conflito e estrutura de grupo. In: FILHO, Evaristo de Moraes. Georg Simmel: sociologia. São Paulo: Ática, 1983.

SIMMEL, Georg. Sociabilidade - um exemplo de sociologia pura ou formal. In: FILHO, Evaristo de Moraes. Georg Simmel: sociologia. São Paulo: Ática, 1983.

SIMMEL, Georg. A metrópole e a vida mental. In: VELHO, Otavio. $O$ fenômeno urbano. Rio de Janeiro: Zahar, 1967. 